\title{
Apple Pollination Biology for Stable and Novel Fruit Production: Search System for Apple Cultivar Combination Showing Incompatibility, Semicompatibility, and Full-Compatibility Based on the S-RNase Allele Database
}

\author{
Shogo Matsumoto \\ Graduate School of Bioagricultural Sciences, Nagoya University, Chikusa, Nagoya 464-8601, Japan \\ Correspondence should be addressed to Shogo Matsumoto; shogo@agr.nagoya-u.ac.jp
}

Received 13 February 2014; Revised 25 March 2014; Accepted 4 April 2014; Published 30 April 2014

Academic Editor: Othmane Merah

Copyright (C) 2014 Shogo Matsumoto. This is an open access article distributed under the Creative Commons Attribution License, which permits unrestricted use, distribution, and reproduction in any medium, provided the original work is properly cited.

Breeding and cultivation of new apple cultivars are among the most attractive and important issues for apple researchers. As almost all apple cultivars exhibit gametophytic self-incompatibility (GSI), cross-pollination between genetically different cultivars and species is essential not only for stable fruit production, but also for breeding of new cultivars. For cross-pollination by insect or hand pollination, pollen viability and pistil fertility are key factors, but also the mechanism of GSI has to be taken into account. This paper reviews the germination rate of pollen after storage in different conditions, at different periods of flowering, and in combination with pistil fertility and cross-compatibility among wild-, crab-, and cultivated apples. Furthermore, suitable cultivar combinations for new attractive apple cultivars based on GSI are explored. Especially, details about S-genotypes of apple cultivars, which are present in recent cultivar catalogues, are introduced together with a newly established on-line searchable database of $S$-genotypes of cultivars, wild apples and crab apples that shows incompatibility, semicompatibility, and full-compatibility.

\section{Introduction}

Apple (Malus $\times$ domestica Borkh.) is one of the most important and widely cultivated fruit around the world. It is the second most important fruit (75.5 million $\mathrm{t} /$ year) in the world following bananas (107.1 million t/year) [1], and China is the largest producer, while the USA is second. Over 7,500 apple cultivars are known [2] and used not only for fresh consumption, but also for consumption as processed materials, such as juice, pie, or cider. Apple and apple products, including juices and extracts, have beneficial effects on Alzheimer's disease, bone health, cognitive decline during normal aging, diabetes, and gastrointestinal protection from drug injury [3]. Apple is the most produced fruits in temperate climate areas and is expanding into subtropical and tropical areas [4]. However, recent global climate changes manifested in rising temperatures and late frosts in the flowering season caused poorer coloring of apple fruit skin and frost damage to pistils [5].
Pollination is a key event for stable apple production, and fertilization normally occurs between genetically different cultivars. In this review, I will focus on apple pollination, including pollen germination, pistil fertilization. and crosscompatibility. In addition, a searchable database system for apple cultivar combination evaluating the compatibility of cultivars is presented.

\section{Pollen Storage and Germination and Pistil Fertilization}

The time for flowering initiation is different among apple species and cultivars. For instance, pollenizers, including wild and crab apples, flower earlier than most other commercial cultivars. Although the pollen of early-flowering pollenizers cannot directly contribute to the pollination of commercial cultivars, it is desirable to store it as an additional pollen source for hand pollination. Actually, artificial pollination 


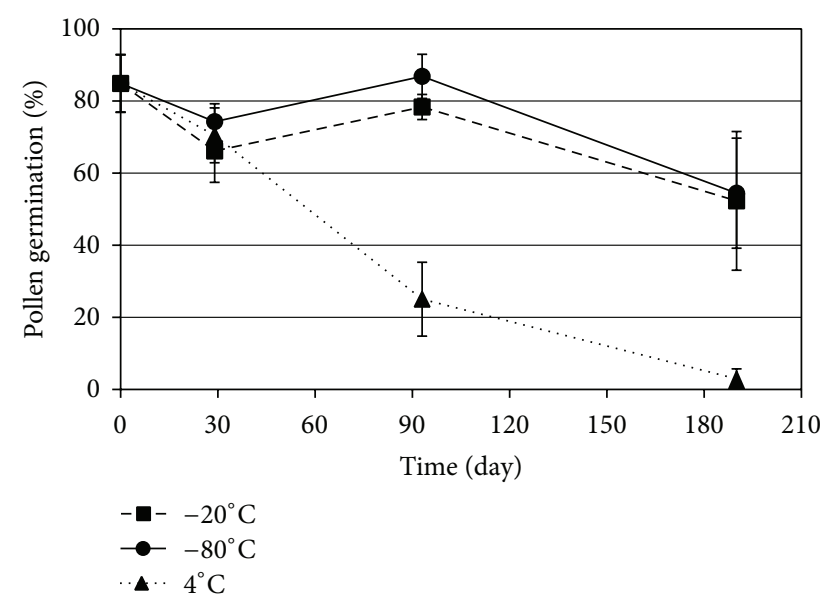

FIGURE 1: Pollen germination rate (\%) of "Fuji" under three temperature conditions $\left(4^{\circ} \mathrm{C},-20^{\circ} \mathrm{C}\right.$, and $\left.-80^{\circ} \mathrm{C}\right)$.

is necessary for stable apple production under unexpected weather conditions, such as low temperature not suitable for other pollinators. In some cases, stored pollen might be the used exclusively. Stored pollen is also important for breeding of new cultivars. For instance, the commercial cultivar "Orin" flowers a few days earlier than most other commercial cultivars. In this case, stored pollen of commercial cultivars has to be used for cross-pollination of "Orin" when aiming for new cultivars based on "Orin".

Apple pollen keeps its viability for seven months if stored at $-80^{\circ} \mathrm{C}$ under low relative humidity [6]. I investigated the germination rate of "Fuji" pollen, one of the most famous commercial cultivars according to the method described in Matsumoto et al. 2011 [7]. Results and discussion, as shown in Figure 1, are as follows. The viability of stored pollen was slightly reduced compared to fresh pollen but persisted up to six months at $-20^{\circ} \mathrm{C}$ and $-80^{\circ} \mathrm{C}$. In contrast, viability was almost lost after six months at $4^{\circ} \mathrm{C}$. The same tendency was also observed for "Maypole," a typical pollenizer genotype (results not shown). Concluding from the results, it seems reasonable that stored pollen of pollenizers kept at $4^{\circ} \mathrm{C}$ should only be used as a pollen source for cultivars which flower during the same season. When pollen is stored with the intention of breeding or production in the coming season, storage should be performed at $-20^{\circ} \mathrm{C}$ or $-80^{\circ} \mathrm{C}$.

Flowering period also differs among apple species and cultivars. The flowering period from the opening of the central flower to the abscission of the petals is influenced by the weather. It took eight days for "Gala;" nine days for "Elster," "Golden Delicious," "Granny Smith," and "Fuji" at an average temperature of $15.8^{\circ} \mathrm{C}$ in $2007 ; 12$ days for "Golden Delicious" and "Granny Smith;" 13 days for "Gala" and "Elster;" and 14 days for "Fuji" at $13.3^{\circ} \mathrm{C}$ in 2008 coupled with a lower amount of sunny hours at Nagylapos, Eastern Hungary [8]. In the case of commercial cultivars, the central flower opened first followed by the laterals [8]. I observed that the opening of the central flower of "Fuji" was between half a day and one day earlier than that of the laterals at Nagoya, Japan, in 2013 (the temperature during the flowering period at day time was $13-23^{\circ} \mathrm{C}$ ). Also in the case of "Maypole," the central flower opened first at all 5 to 7 flower clusters investigated. However, some clusters had two central flowers and opened one of these first (Figure 2(a)). The period between opening of the central flower and the opening of the lateral flowers was 1.5-2.5 days in "Maypole," which was shorter compared to "Fuji" (3-4 days). The central flowers had an intense but short stigmatic activity, whereas lateral flowers had a discrete but much longer stigmatic activity [9]. Since many flower clusters of "Maypole" opened sequentially, the flowering period was longer (Figure 2(b)). The effective pollination period of "Golden Delicious" lasted for five to eight days [10]. In the case of "Fuji," pistil fertility seemed to be maintained until four days after flowering at the same level regardless of pollination, but once fertilization occurred, the pistil lost its fertility within 24 hours [11]. Pollenizers in full bloom that are shifted more than 24 hours seem thus unnecessary at an orchard with only a single commercial cultivar, since repeated artificial pollination must be done within 24 hours [11].

\section{Cross-Compatibility among Wild Apples, Crab Apples (Pollenizers), and Cultivars}

As apple (Malus $\times$ domestica) shows gametophytic self- and cross-incompatibility, and at least two genetically distinct cultivars are necessary for stable apple production. Selfcompatible apple cultivars are not known globally, but "Megumi" is one of the few self-compatible cultivars. However also here cross-pollination of "Megumi" is recommended for stable fruit production since the ratio of fruit set and seed number per fruit of Megumi $\times$ Megumi is 24.0 $88.8 \%$ and 4.2 , respectively [12].

The gametophytic self-incompatibility (GSI) system in apple is controlled by a multiallelic single locus, called $S$ locus $[13,14]$. The genes responsible for apple GSI, (S-RNase as the pistil factor and $S F B / S L F$ as the pollen factor) have been cloned $[15,16]$. Both, $S$-RNase and SFB/SLF are located at the $S$-locus, and their combined alleles are called $S$-haplotype for they are tightly linked. In the GSI system, if one of the $S$-haplotypes of the pistil matches with that of pollen, pollen tube growth in the style is arrested. For instance, a cross between cultivars $S_{1} S_{2}$ and $S_{1} S_{2}$ results in crossincompatibility, whereas a cross between cultivars $S_{1} S_{2}$ and $S_{3} S_{4}$ results in cross-compatibility. In the case of crossing $S_{1} S_{2}$ and $S_{2} S_{3}$, semicompatibility would occur since pollen of the $S_{2}$-haplotype will be rejected by the $S_{2}$-haplotype of the pistil, but that of $S_{3}$-haplotype will not be rejected. Sometimes these semicompatible crossings cause undesirable fruit malformations, such as lopsided fruits. This might be caused by inadequate seeds in the fruit probably due to insufficient effective pollen at the time of pollination [11, 17, 18]. In addition to the $S$-haplotype, additional information about minor apple species and old cultivars, such as crab apples, is also important because apple orchards that consisted of a single cultivar, wild, and old cultivars have to be utilized as pollenizers for stable apple production. Moreover, information on the $S$-genotypes of apple is not only important 


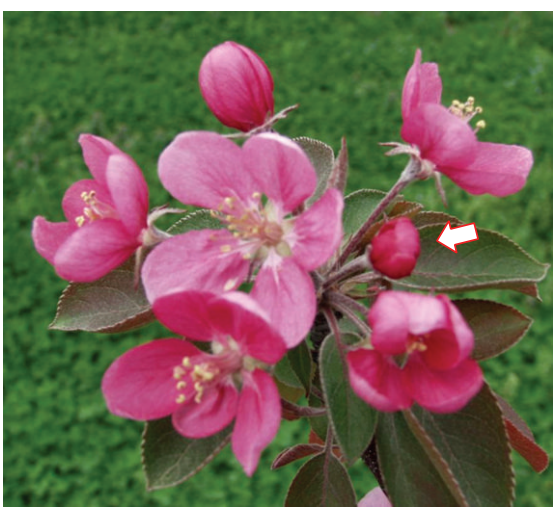

(a)

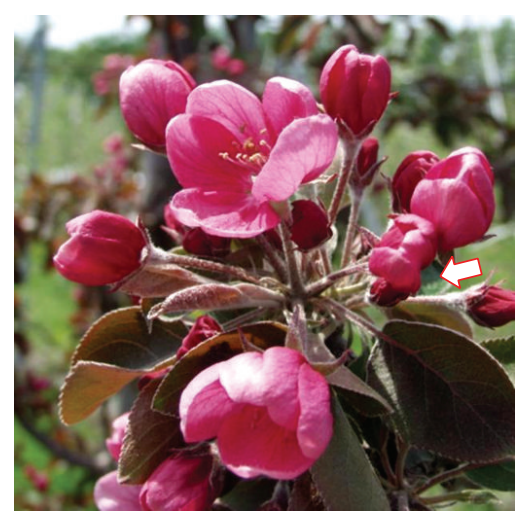

(b)

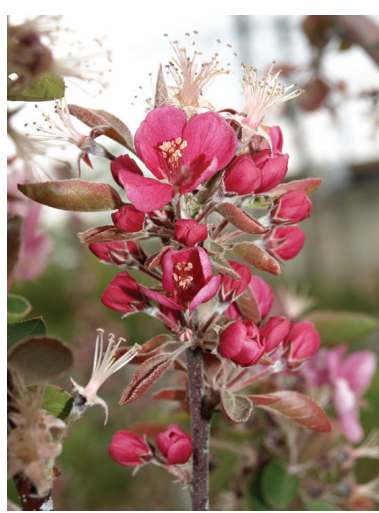

(c)

Figure 2: (a) A "Maypole" flower cluster having two central flowers. One central flower fully opened, but the other one did not open (indicated by arrow). (b) Flower of "Maypole".

for cultivar combination for stable apple fruit production, but also for the breeding of new cultivars.

Nowadays apple breeding using "Fuji" as either ovule or pollen parent is becoming increasingly popular in Japan and the genetic background of cultivars is becoming more homogenous. A lot of sports of "Fuji" were also found. For instance, cross-incompatibility occurs in any combinations within "Fuji" $\left(S_{1} S_{9}\right)$, "Akifu 1" $\left(S_{1} S_{9}\right.$; sport of "Fuji"), "Akifu 4" $\left(S_{1} S_{9}\right.$; sport of "Fuji”), "Akifu 7 " $\left(S_{1} S_{9} S_{28}\right)$, "Alps Otome" $\left(S_{1} S_{9}\right)$, "Akiyo" $\left(S_{1} S_{9}\right.$; "Senshu" × "Fuji"), "Aofu 1" $\left(S_{1} S_{9}\right.$; sport of "Fuji"), "Aori 6 Gou" $\left(S_{1} S_{7} S_{9}\right.$; "Fuji” × "Jonathan"), "Benishigure" $\left(S_{1} S_{9}\right.$; sport of "Fuji"), "BeniShogun" $\left(S_{1} S_{9}\right.$; sport of "Yataka"), "Fukunishiki" ( $S_{1} S_{9}$; "Ralls Janet" × "Delicious"), "Gunfu 1" $\left(S_{1} S_{9}\right.$; sport of "Fuji"), "Gunfu 2" $\left(S_{1} S_{9}\right.$; sport of "Fuji"), "Hac 9" ( $S_{1} S_{9}$; "Fuji" × “Tsugaru"), "Highland Fuji" $\left(S_{1} S_{9}\right.$; sport of "Fuji”), "Hirosaki Fuji" $\left(S_{1} S_{9}\right.$; sport of "Fuji"), "Hokuto" $\left(S_{1} S_{7} S_{9}\right.$; "Fuji" × "Rerol1"), "Kaori" $\left(S_{1} S_{9}\right.$; "Richared Delicious" $\times 111$ Gou ("Ralls Janet" $\times$ "Delicious"), "Kinichiro Fuji" ( $S_{1} S_{9}$; sport of "Fuji"), "Korin" $\left(S_{1} S_{9}\right.$; sport of "Fuji"), "Misora No Red" ( $S_{1} S_{9}$; "Yoko" × "Senshu”), "Morifu 1 " $\left(S_{1} S_{9}\right.$; sport of "Fuji”), "Nagafu 1" $\left(S_{1} S_{9}\right.$; sport of "Fuji”), "Nagara" $\left(S_{1} S_{9}\right.$; sport of "Fuji"), "Ryoka No Kisetsu" $\left(S_{1} S_{9}\right.$; sport of "Fuji”), "Sairai" $\left(S_{1} S_{9}\right)$, "Shinko" $\left(S_{1} S_{9}\right.$; "Ralls Janet" $\times$ "Jonathan"), "Takano Wase" $\left(S_{1} S_{9}\right.$; sport of "Fuji”), "Takita" $\left(S_{1} S_{9} S_{10}\right)$, and "Yataka" $\left(S_{1} S_{9}\right.$; sport of "Fuji"). In addition, pollen viability of triploid cultivars, such as "Jonagold" and "Mutsu," is low since triploids have 51 chromosomes and the chromosomes are unequally divided during meiosis. These cultivars cannot be used as pollenizers for other cultivars.

Using a $S$-RNase allele specific polymerase chain reaction (PCR)-restriction fragment length polymorphism (RFLP) method developed by us $[19,20]$ and other groups in Belgium [21-24], China [25], Korea [26-28], Israel [29, 30], and U.S.A. [31], we have determined the $S$-RNase genotypes of new apple cultivars and selections produced in Japan to know their cross-compatibility with pollenizers and also to use them in a breeding program. Results and discussion are as follows. The S-RNase genotypes of K-13 and Kurosawa 4 Gou (Table 1 Nos. 2 and 9) failed to match any of the expected S-RNase genotypes based on their purported parents. We previously confirmed that "Komitsu" was produced by "Jonathan" $\times$ "Starking Delicious," not by "Starking Delicious" $\times$ "Jonathan" [32]. Similarly, K-13 ( $S_{3} S_{7}$; Table 1 No. 2) appeared to be derived from the cross "Shinano Gold" $\left(S_{1} S_{3}\right) \times$ "Tsugaru" $\left(S_{3} S_{7}\right)$, rather than "Tsugaru" $\left(S_{3} S_{7}\right) \times$ "Shinano Gold" $\left(S_{1} S_{3}\right)$. Another possibility of K-13 $\left(S_{3} S_{7}\right)$ origin is a sport of "Tsugaru" $\left(S_{3} S_{7}\right)$. "Kurosawa 4 Gou" $\left(S_{1} S_{9}\right)$ also seemed to be a sport of "Fuji" $\left(S_{1} S_{9}\right)$. From their fruit and branch characteristics, we speculated that the paternal parent and parents of $\mathrm{K}$ $15\left(S_{7} S_{9}\right)$ and K-19 $\left(S_{3} S_{7}\right)$ (Table 1, No. 4 and 8) were likely to be "Fuji" $\left(S_{1} S_{9}\right)$ and "Shinano Gold" $\left(S_{1} S_{3}\right) \times$ "Tsugaru" $\left(S_{3} S_{7}\right)$ or "Shinano Sweet" $\left(S_{1} S_{7}\right)$. From the $S$-RNase genotypes of RYOKU AP-8, RYOKU AP-9, RYOKU AP-11, RYOKU AP-12, and RYOKU AP-13 (Table 1, Nos. 12, 13, 15-17), their ovule parents "Shinano Red" (RYOKU AP-8, RYOKU AP9, RYOKU AP-11 and RYOKU AP-13) and "Shinano Sweet" (RYOKU AP-12) might be wrong. The S-RNase genotypes of the remaining new cultivars and selections: Hayashi 7 Gou, K-14, K-16, K-17, K-18, Nakazawa 1 Gou, Redfield and RYOKU AP-10 (Table 1 Nos. 1, 3, 5-7, 10, 11, 14) matched one of the expected $S$-RNase genotypes from their reputed parents.

\section{The Search System for Apple Cultivar Combination Showing Incompatibility, Semicompatibility, and Full-Compatibility Based on an S-RNase Allele Database}

We have developed a search system for apple cultivar combination showing incompatibility, semicompatibility, and fullcompatibility. Materials and methods are as follows. Construction of the search system began on the homepage using a JavaScript program. First, the apple $S$-RNase allele genotype information program "apples-1.0.0.js," which determines the operation on a homepage, was created using jQuery. Next, "index.html," which converts picture information on a homepage to HTML format, was created. A file of three separate HTML forms was created as a framework in which search 
TABLE 1: S-RNase genotypes of 17 new apple cultivars including their selection.

\begin{tabular}{|c|c|c|c|}
\hline Number & Cultivar & Reputed parentage & S-RNase genotype \\
\hline 1 & Hayashi 7 Gou & Sport of "Hayashi 1 Gou" $\left(S_{3} S_{7}\right)$ & $S_{3} S_{7}$ \\
\hline 2 & $\mathrm{~K}-13$ & "Tsugaru" $\left(S_{3} S_{7}\right) \times$ "Shinano Gold"+ $\left(S_{1} S_{3}\right)$ & $S_{3} S_{7}$ \\
\hline 3 & K-14 & "Tsugaru" $\left(S_{3} S_{7}\right) \times$ "Sansa" $\left(S_{5} S_{7}\right)$ & $S_{5} S_{7}$ \\
\hline 4 & K-15 & “Tsugaru" $\left(S_{3} S_{7}\right) \times$ Unknown $^{\neq}$ & $S_{7} S_{9}$ \\
\hline 5 & K-16 & "Fuji" $\left(S_{1} S_{9}\right) \times$ "Goldroman" $\left(S_{1} S_{7}\right)$ & $S_{1} S_{7}$ \\
\hline 6 & K-17 & "Fuji" $\left(S_{1} S_{9}\right) \times$ "Goldroman" $\left(S_{1} S_{7}\right)$ & $S_{1} S_{7}$ \\
\hline 7 & K-18 & "Shinano Gold" $\left(S_{1} S_{3}\right) \times$ "Beniroman" $\left(S_{3} S_{5}\right)$ & $S_{3} S_{5}$ \\
\hline 8 & K-19 & Unknown $^{\neq} \times$Unknown $^{\neq}$ & $S_{3} S_{7}$ \\
\hline 9 & Kurosawa 4 Gou & "Fuji" $\left(S_{1} S_{9}\right) \times$ "Akane" $\left(S_{7} S_{24}\right)$ & $S_{1} S_{9}$ \\
\hline 10 & Nakazawa 1 Gou & Sport of "Shinano Sweet" $\left(S_{1} S_{7}\right)$ & $S_{1} S_{7}$ \\
\hline 11 & Redfield & Wolf River $\left(S_{3} S_{16}\right) \times M$. pumila Niedzwetzkyana $\left(S_{3} S_{x}\right)$ & $S_{3} S_{x}$ \\
\hline 12 & RYOKU AP-8 & Chance seedling of "Shinano Red" $\left(S_{3} S_{10}\right)$ & $S_{3} S_{10}$ \\
\hline 13 & RYOKU AP-9 & Chance seedling of "Shinano Red" $\left(S_{3} S_{10}\right)$ & $S_{3} S_{10}$ \\
\hline 14 & RYOKU AP-10 & Sport of "Redfield" $\left(S_{3} S_{x}\right)$ & $S_{3} S_{x}$ \\
\hline 15 & RYOKU AP-11 & Chance seedling of "Shinano Red" $\left(S_{3} S_{10}\right)$ & $S_{3} S_{10}$ \\
\hline 16 & RYOKU AP-12 & Chance seedling of "Shinano Sweet" $\left(S_{1} S_{7}\right)$ & $S_{1} S_{7}$ \\
\hline 17 & RYOKU AP-13 & Chance seedling of "Shinano Red" $\left(S_{3} S_{10}\right)$ & $S_{3} S_{10}$ \\
\hline
\end{tabular}

${ }^{+}$Incorrect parentage indicated by this work is bolded.

* Unknown: ovule or pollen parent is unknown.

results are displayed on separate windows established for in, semi- and full-compatibility. The search system homepage built in this manner can be accessed from the following URL: http://www.agr.nagoya-u.ac.jp/ hort/apple/ [7]. Information on the S-RNase allele nomenclature, the PCR-RFLP method including primers and PCR conditions, is also accessible via the search system homepage.

4.1. Database of Apple S-RNase Genotypes. Currently, we have identified the S-RNase genotypes of more than 600 apple cultivars and species using the $S$-RNase allele specific polymerase chain reaction (PCR)-restriction fragment length polymorphism (RFLP) method [7]. The investigated $S$-genotypes included data of $S$-genotypes kindly provided by Dr. T. Akada and Dr. K. Sakurai. The names of the parent of each apple and additional reference information were compiled in a Microsoft Office Excel 12.3.2 file which was named "Apple-Sgene.xls" file. The created file was changed into a flat file "sample.xml" of XML format by using an Excel macro. The numerical number was input within the file for reference information, which was embedded on the retrieval program. Moreover, renewal of the XML file on a web server was performed using FTP soft FileZilla. Version up of the file through incorporating the published $S$-RNase allele data of cultivars in the world is under progressing [21, 23, 2528, 30, 33-37].

4.2. The Search System for Apple Cultivar Combination Shows Full-, Semi-, and Incompatibility. The starting point of the search system is reached by accessing the URL (http://www.agr.nagoya-u.ac.jp/ hort/apple/) and entering an appropriate apple cultivar, species, or linage name in the box on the homepage. The search system will attempt to autocomplete the user entries. This way, even if the spelling of the name is ambiguous, the correct name can be easily chosen from the list of indicated candidates (Figure 3). Following the input of an appropriate name, the user has to decide whether the selected cultivar is used as either ovule parent (mother) or pollen parent (father). After clicking the search button, three windows show cultivars, species, or selections with in-, semi- and full-compatibility, respectively, displayed together with their S-genotypes and reference numbers (Figure 3). Full reference information is displayed as a pop-up by hovering the cursor over the reference number.

4.3. Data Handling among Diploids, Triploids, and Tetraploids Genotypes. Using the search system, combinations of apple cultivars, species, and selections showing in-, semi- and fullcompatibility are easily obtained. For instance, if "Fuji" $\left(S_{1} S_{9}\right)$ is chosen as an ovule or pollen cultivar, all of the in-, semiand full-compatible apples with "Fuji" in the database, such as "Alps Otome" $\left(S_{1} S_{9}\right)$ having the same $S$-RNase alleles of "Fuji," "Shinano Sweet" $\left(S_{1} S_{7}\right)$ having one common S-RNase allele $S_{1}$ with "Fuji", and "Tsugaru" $\left(S_{3} S_{7}\right)$ having completely different $S$-RNase alleles with "Fuji", respectively, are shown in each window.

In the case of diploid pollenizers which have novel unidentified $S_{x^{-}}$and $S_{y}$-RNase alleles, cross-pollination can result in full-, semi-, or incompatibility (Figure 4(a)). In these cases, the search system displays all possible results in their respective windows.

Crosses of Diploid $\times$ tetraploid cultivars, triploid $\times$ tetraploid cultivars and tetraploid $\times$ tetraploid cultivars can result in full compatibility, incompatibility, or different degrees of semicompatibility, because diploid pollen can have more than one $S$-allele. For instance, pollinating $S_{1} S_{9}$ diploid 


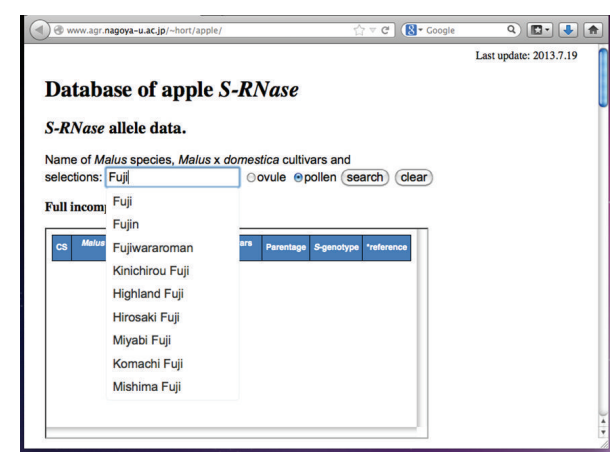

(a)

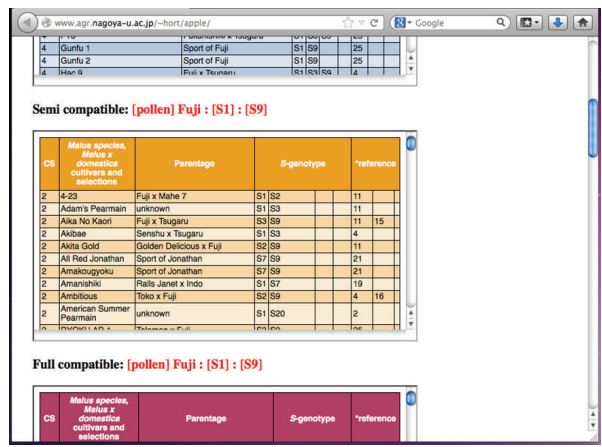

(c)

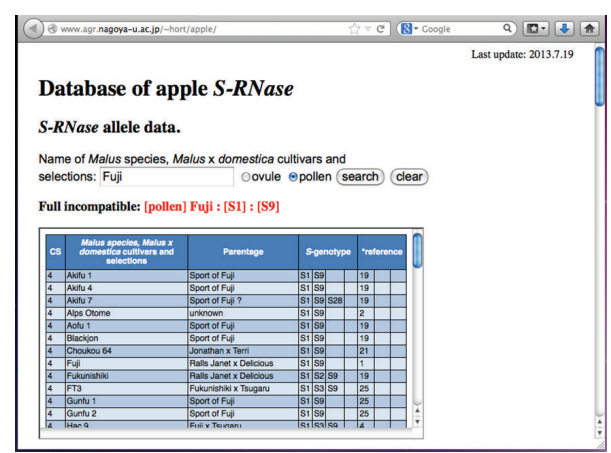

(b)

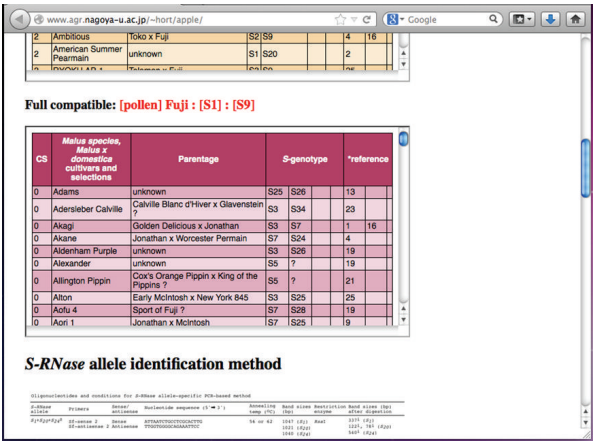

(d)

FIGURE 3: Representative screen shots of the search system. (a) "Fuji" was selected to search cultivars for investigation of cultivars, species, and selections showing full-, semi- and incompatibility with "Fuji." (b) Search result: cultivars incompatible with "Fuji." (c) Search result: cultivars semicompatible with "Fuji." (d) Search result: cultivars fully compatible with "Fuji."

"Fuji" with $S_{1} S_{1} S_{9} S_{9}$ tetraploid “Tensei” pollen results in 50\% semicompatibility, since only $S_{1} S_{9}$ heteroallelic pollen, but not $S_{1} S_{1}$ or $S_{9} S_{9}$ homoallelic pollen, leads to fertilization in the pistil of "Fuji" (Figure 4(b)). Pollinating $S_{7} S_{9}$ diploid "Jonathan" with "Tensei" pollen results in $75 \%$ semicompatibility, since also $S_{1} S_{1}$ homoallelic pollen, in addition to $S_{1} S_{9}$ heteroallelic pollen, is not rejected in the pistil of "Fuji" [38].

Similarly, pollinating $S_{1} S_{2} S_{9}$ triploid "Fukunishiki" with $S_{1} S_{1} S_{9} S_{9}$ tetraploid "Tensei" pollen results in 50\% semicompatibility, but when $S_{2} S_{3} S_{9}$ triploid "Jonagold" is pollinated with "Tensei" pollen 75\% semicompatibility is observed (Figure 4(c)). Pollinating "Tensei" with $S_{7} S_{7} S_{9} S_{9}$ tetraploid "Welday Jonathan" pollen or "Welday Jonathan" with "Tensei" pollen results in $75 \%$ semicompatibility (Figure $4(\mathrm{~d})$ ). The search system does not distinguish between different degrees of semicompatibility and all semicompatible combinations are presented together in the corresponding window.

The results of triploid cultivar $\times$ diploid cultivar and tetraploid cultivar $\times$ diploid cultivar are displayed only on the basis of their $S$-genotypes. For instance, it is expected that triploid "Fukunishiki" $\left(S_{1} S_{2} S_{9}\right) \times$ diploid "Fuji" $\left(S_{1} S_{9}\right)$, "Fukunishiki" $\times$ diploid "Shinano Sweet" $\left(S_{1} S_{7}\right)$, and "Fukunishiki" $\times$ diploid "Tsugaru" $\left(S_{3} S_{7}\right)$ result in incompatible, semicompatible and full-compatible, respectively, and "Fukunishiki" $\times$ diploid "Cox"s Pomona' $\left(S_{1} S_{x}\right)$, "Fukunishiki" $\times$ diploid "Snowdrift" $\left(S_{25} S_{x}\right)$ and "Fukunishiki" $\times$ diploid "Dolgo"
$\left(S_{x} S_{y}\right)$ result in semicompatible, full-compatible, and fullcompatible, respectively (Figure 4(e)). Similarly, tetraploid "Tensei" $\times$ diploid "Fuji" $\left(S_{1} S_{9}\right)$, "Tensei" $\times$ diploid "Shinano Sweet" $\left(S_{1} S_{7}\right)$ and "Tensei" $\times$ diploid "Tsugaru" $\left(S_{3} S_{7}\right)$ results in incompatible, semicompatible, and full-compatible, respectively, and "Tensei" $\times$ diploid "Cox"s "Pomona" $\left(S_{1} S_{x}\right)$, "Tensei" $\times$ diploid "Snowdrift" $\left(S_{25} S_{x}\right)$ and "Tensei" $\times$ diploid "Dolgo" $\left(S_{x} S_{y}\right)$ result in semicompatible, full-compatible, and full-compatible, respectively (Figure 4(f)).

The determination of $S$-RNase genotypes of new cultivars and selections is an ongoing activity and new results will be implemented into the database through regular updates.

\section{Suitable Cultivar Combination for Production of Novel Cultivars Including New Red-Fleshed Apple}

Recently, the breeding of functional fruits containing biologically active components attracted attention. Anthocyanins are the main pigments in fruits. Anthocyanins possess strong antioxidant activity and are potent inhibitors of lipid peroxidation, which plays a role in the prevention of cardiovascular and neuronal illnesses, cancer, and diabetes [39]. In recent years, many studies have shown an effect of an anthocyaninrich diet on the prevention of age-related neural disorders such as Alzheimer's disease [40, 41]. 


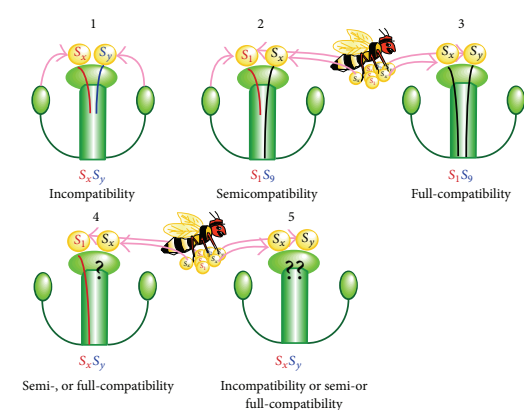

(a)

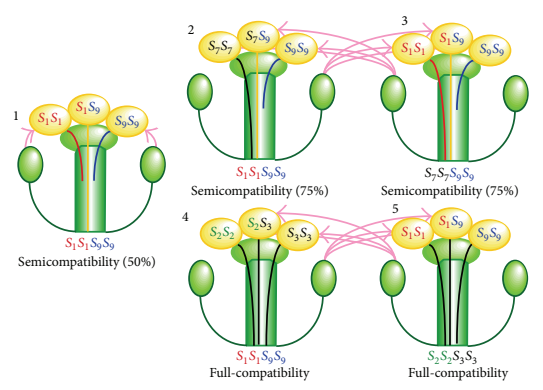

(d)

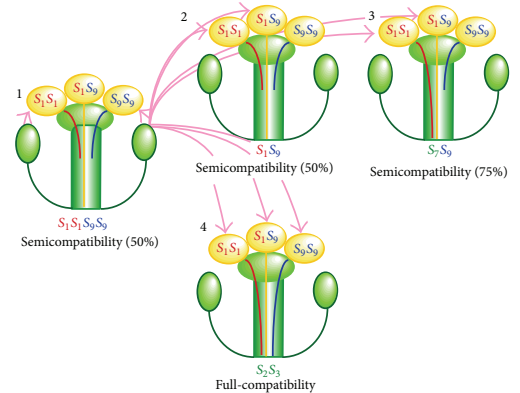

(b)

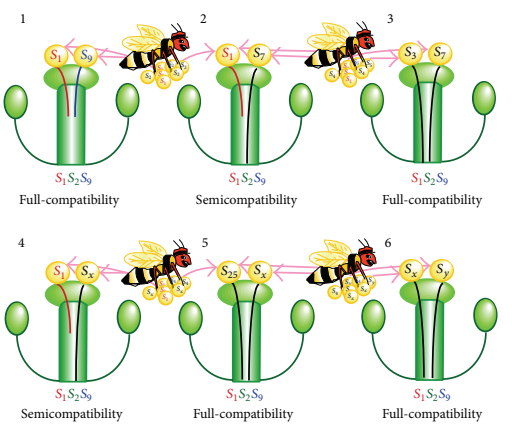

(e)

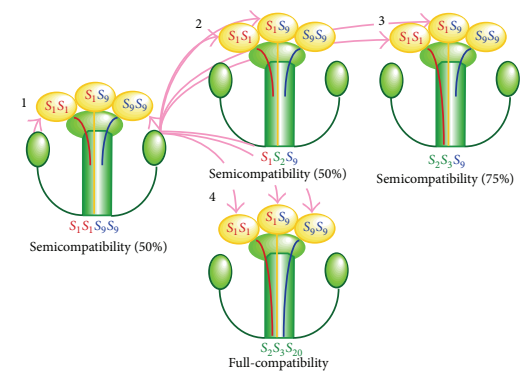

(c)

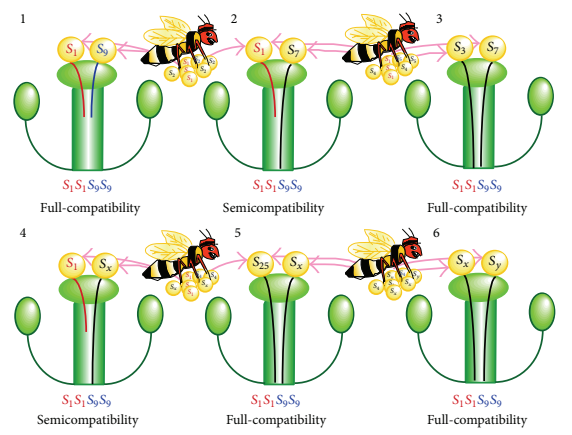

(f)

Figure 4: (a) Results of self-pollination of diploid "Dolgo" (1), diploid "Fuji” × diploid "Cox"s Pomona' (2), "Fuji" × "Dolgo" (3), "Dolgo" × "Cox"s Pomona' (4), and "Dolgo" × diploid "Pink Perfection" (5). (b) Results of self-pollination of tetraploid "Tensei" (1), diploid "Fuji" $\times$ "Tensei" (2), diploid "Jonathan" × "Tensei" (3), and diploid "Golden Delicious" × "Tensei" (4). (c) Results of self-pollination of tetraploid "Tensei" (1), triploid "Fukunishiki” $\times$ "Tensei” (2), triploid "Jonagold" $\times$ “Tensei” (3), and triploid "Mutsu" $\times$ "Tensei” (4). (d) Results of self-pollination of tetraploid "Tensei" (1), "Tensei" $\times$ tetraploid "Welday Jonathan" (2), "Welday Jonathan" $\times$ "Tensei" (3), "Tensei” $\times$ tetraploid "Doud Golden Delicious" (4), and "Doud Golden Delicious" × "Tensei” (5). (e) Results of triploid "Fukunishiki" $\times$ diploid "Fuji" (1), "Fukunishiki” $\times$ diploid "Shinano Sweet" (2), "Fukunishiki” $\times$ diploid "Tsugaru” (3), "Fukunishiki” $\times$ diploid "Cox"s Pomona' (4), "Fukunishiki" × diploid "Snowdrift" (5), and "Fukunishiki” $\times$ diploid "Dolgo" (6). (f) Results of tetraploid "Tensei” $\times$ diploid "Fuji” (1), "Tensei" $\times$ diploid "Shinano Sweet" (2), “Tensei” $\times$ diploid "Tsugaru” (3), "Tensei” $\times$ diploid "Cox"s Pomona' (4), “Tensei” $\times$ diploid "Snowdrift" (5), and "Tensei" $\times$ diploid "Dolgo" (6).

In this chapter, I introduce a novel cultivar "Beniroman" and other new red-fleshed apples. "Beniroman" originated from a cross between "Shinano Red" and "Sansa" in 1998 at Kokaen in Iwate in northern Japan. Seeds were germinated in 1999, and 80 seedlings were budded onto JM1 rootstock. Fruits were evaluated in 2008 and 2009, and "Beniroman" was selected. "Beniroman" came to full-bloom flowering two days before "Fuji" in "Kokaen" at 2008, which is typically at the end of April. "Beniroman" fruit ripens in the middle of August, which makes it one of the earliest cultivars in Japan. We made the cultivar in "Togokusan Fruit Park" located close to Nagoya in Aichi in central Japan, and surprisingly, it ripened at the end of July with high red pigmentation despite extremely high temperatures $\left(33-35^{\circ} \mathrm{C}\right.$ during daytime) (Figure 5). The S-RNase genotype of "Beniroman" was identified as $S_{3} S_{5}$. Development of novel cultivars derived from "Beniroman" with stable red skin pigmentation under high temperatures can be initiated using the search system as outlined in chapter 4 .

There are two types of red-fleshed apples. Type 1 redfleshed apples mainly were derived from Malus pumila var. Niedzwetzkyana and its derivatives show red pigmentation throughout the fruit; from fruit set through maturity [42].
In addition to the flesh and the skin of the fruits, vegetative tissues including leaves, branches, and floral organs are also highly pigmented, but in case of "Maypole," cortex pigmentation disappears gradually with maturity $[42,43]$. Type 2 red-fleshed apples derived from "Pink Pearl" show a green-leaf and red-fleshed phenotype, and their cortex is specifically pigmented at the late stage of fruit development (Figure 5) [43]. We found that the red-fleshed trait of "Pink Pearl" is tightly linked with its $S_{3}$-RNase allele located within the $S$-locus responsible for the gametophytic self- and cross-incompatibility system in apple [44]. Using this tight linkage, we found suitable cultivar combinations for efficient production of various red-fleshed apples (Table 2). Recently, new MYB-transcription factors named MdMYB110a and $M d M Y B 110 a_{-} J P$ responsible for red-fleshed trait in the type 2 were isolated from fruits from a cross between cv "Sciros" and a red-freshed cv "Sangrado" open pollinated (OP) seedling and JPP35 ("Jonathan" $\times$ "Pink Pearl"), respectively [43, 45].

\section{Conclusion}

Pollination is a key procedure during apple breeding and cultivation. In this paper, I introduced the mechanism of 


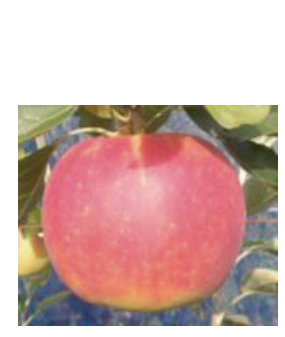

(a)

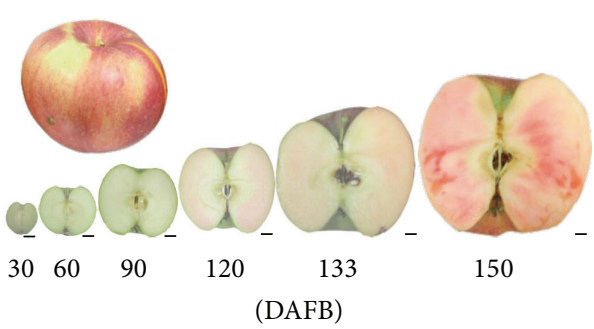

(b)

Figure 5: (a) A mature fruit of "Beniroman" produced at “Togokusan Fruit Park". (b) Fruit development series of "Ruby Sweet" produced at NARO Institute of Fruit Tree Science (NIFTS). Scale bar $1 \mathrm{~cm}$.

TABLE 2: Cross-combination for efficient production of red-fleshed apple progenies.

\begin{tabular}{ll}
\hline Ovule cultivar & Pollen cultivar \\
\hline$S_{3}$-absence and $S_{7}$-presence cultivars Akane $\left(S_{7} S_{24}\right)$, & Red-fleshed cultivar and selection of $S_{3} S_{7}$ genotype \\
Himekami $\left(S_{7} S_{9}\right)$, Iwakami $\left(S_{1} S_{7}\right)$, Jonathan $\left(S_{3} S_{7}\right)$, & JPP35, No. 3, 37, 42,50 and 69 progenies from "Shinano \\
Kiou $\left(S_{1} S_{7}\right)$, Orin $\left(S_{2} S_{7}\right)$, Sansa $\left(S_{5} S_{7}\right)$, Senshu $\left(S_{1} S_{7}\right)$, & Sweet" $\times$ JPP35 \\
Shinano Dolce $\left(S_{2} S_{7}\right)$, Shinano Sweet $\left(S_{1} S_{7}\right)$ & \\
\hline$S_{3}$-absence and $S_{1}$-presence cultivars American & Red-fleshed cultivar and selection of $S_{1} S_{3}$ genotype No. \\
Summer Pearmain $\left(S_{1} S_{20}\right)$, Fuji $\left(S_{1} S_{9}\right)$, Iwakami $\left(S_{1} S_{7}\right)$, & $29,38,41$ and 44 progenies from "Shinano Sweet" $\times$ \\
Kiou $\left(S_{1} S_{7}\right)$, Ralls Janet $\left(S_{1} S_{2}\right)$, Ryoka No Kisetsu $\left(S_{1} S_{9}\right)$, & JPP35 \\
Senshu $\left(S_{1} S_{7}\right)$, Shinano Sweet $\left(S_{1} S_{7}\right)$ & \\
\hline
\end{tabular}

apple self- and cross-incompatibility based on pollen-pistil interactions. Especially, I showed details about $S$-genotypes of apple cultivars which are present in recent cultivar catalogues. An online database (Search System) of S-genotypes of cultivars, wild apples, and crab apples was introduced that allows the user to search for apple cultivar combinations that result in incompatibility, semicompatibility and full-compatibility. This system will be of high value for anyone interested in apple breeding and cultivation.

\section{Conflict of Interests}

The author declares that there is no conflict of interests regarding the publication of this paper.

\section{Acknowledgments}

The author is indebted to Mr. T. Okawa for his valuable assistance in database construction. The author also wishes to thank Dr. S. Reuscher for critical reading of the paper and Ms. M. Yamaguchi for her valuable technical assistance. This research was partly supported by the 37 th Research Support of the Matsushima Horticultural Development Foundation.

\section{References}

[1] FAO, 2011, http://faostat3.fao.org/faostat-gateway/go/to/download/Q/QC/E.

[2] A. T. G. Elzebroek and K. Wind, "Edible fruits and nuts," in Guide to Cultivated Plants, A. T. G. Elzebroek and K. Wind, Eds., pp. 25-131, CAB International, Wallingford, UK, 2008.
[3] D. A. Hyson, "A comprehensive review of apples and apple components and their relationship to human health," Advances in Nutrition, vol. 2, no. 5, pp. 408-420, 2011.

[4] S. Brown, "Apple," in Fruit Breeding, M. L. Badenes and D. H. Byrne, Eds., pp. 329-367, Springer, New York, NY, USA, 2012.

[5] T. Sugiura, H. Kuroda, and H. Sugiura, "Influence of the current state of global warming on fruit tree growth in Japan," Horticultural Research, vol. 6, no. 2, pp. 257-263, 2007.

[6] A. Imani, K. Barzegar, S. Piripireivatlou, and S. H. Masomi, "Storage of apple pollen and in vitro germination," African Journal of Agricultural Research, vol. 6, no. 3, pp. 624-629, 2011.

[7] S. Matsumoto, K. Okada, A. Kojima, K. Shiratake, and K. Abe, " $S$-RNase genotypes of apple (Malus $\times$ domestica Borkh.) including new cultivars, lineages, and triploid progenies," Journal of Horticultural Science and Biotechnology, vol. 86, no. 6, pp. 654-660, 2011.

[8] J. Racskó and D. Miller, "Intra-inflorescence pattern of the opening of apple (Malus domestica Borkh.) flowers," The International Journal of Plant Reproductive Biology, vol. 2, no. 1, pp. 65-77, 2010.

[9] J. M. Losada and M. Herrero, "Flower strategy and stigma performance in the apple inflorescence," Scientia Horticulturae, vol. 150, pp. 283-289, 2013.

[10] V. M. Guerrero-Prieto, A. Rascón-Chu, A. Romo-Chacón et al., "Short communication. Effective pollination period in "RedChief" and "Golden Delicious" apples (Malus domestica Borkh)," Spanish Journal of Agricultural Research, vol. 7, no. 4, pp. 928-932, 2009.

[11] S. Matsumoto, J. Soejima, and T. Maejima, "Influence of repeated pollination on seed number and fruit shape of "Fuji" apples," Scientia Horticulturae, vol. 137, pp. 131-137, 2012.

[12] S. Matsumoto, S. Komori, K. Kitahara, S. Imazu, and J. Soejima, "S-genotypes of 15 apple cultivars and self-compatibility of 
'Megumi,' Journal of the Japanese Society for Horticultural Science, vol. 68, no. 2, pp. 236-241, 1999.

[13] D. de Nettancourt, "Incompatibility in angiosperms," in Monographs on Theoretical and Applied Genetics, R. Frankel, G. A. E. Gal, and H. F. Linskens, Eds., pp. 28-57, Springer, Heidelberg, Germany, 1977.

[14] F. Kobel, P. Steinegger, and J. Anliker, "Weitere untersuchungen über die Befruchtungsverhältnisse der Apfel- und Birnsorten," Landwirtschaftliches Jahrbuch der Schweiz, vol. 53, pp. 160-191, 1939.

[15] W. Broothaerts, G. A. Janssens, P. Proost, and W. F. Broekaert, "cDNA cloning and molecular analysis of two self-incompatibility alleles from apple," Plant Molecular Biology, vol. 27, no. 3, pp. 499-511, 1995.

[16] J. Cheng, Z. Han, X. Xu, and T. Li, "Isolation and identification of the pollen-expressed polymorphic F-box genes linked to the $S$-locus in apple (Malus $\times$ domestica)," Sexual Plant Reproduction, vol. 19, no. 4, pp. 175-183, 2006.

[17] D. Schneider, R. A. Stern, and M. Goldway, "A comparison between semi- and fully compatible apple pollinators grown under suboptimal pollination conditions," HortScience, vol. 40, no. 5, pp. 1280-1282, 2005.

[18] S. Matsumoto, K. Kitahara, H. Komatsu, and K. Abe, "Crosscompatibility of apple cultivars possessing $S$-RNase alleles of similar sequence," Journal of Horticultural Science and Biotechnology, vol. 81, no. 6, pp. 934-936, 2006.

[19] S. Matsumoto and K. Kitahara, "Discovery of a new selfincompatibility allele in apple," HortScience, vol. 35, no. 7, pp. 1329-1332, 2000.

[20] J. Morita, K. Abe, and S. Matsumoto, "S-RNase genotypes of apple cultivars grown in Japan and development of A PCRRFLP method to identify the S6-and S21-RNase alleles," Journal of Horticultural Science and Biotechnology, vol. 84, no. 1, pp. 2934, 2009.

[21] W. Broothaerts, "New findings in apple S-genotype analysis resolve previous confusion and request the re-numbering of some S-alleles," Theoretical and Applied Genetics, vol. 106, no. 4, pp. 703-714, 2003.

[22] G. A. Janssens, I. J. Goderis, W. F. Broekaert, and W. Broothaerts, "A molecular method for $S$-allele identification in apple based on allele-specific PCR," Theoretical and Applied Genetics, vol. 91, no. 4, pp. 691-698, 1995.

[23] I. van Nerum, M. Geerts, A. van Haute, J. Keulemans, and W. Broothaerts, "Re-examination of the self-incompatibility genotype of apple cultivars containing putative "new" S-alleles," Theoretical and Applied Genetics, vol. 103, no. 4, pp. 584-591, 2001.

[24] L. Verdoodt, A. van Haute, I. J. Goderis, K. de Witte, J. Keulemans, and W. Broothaerts, "Use of the multi-allelic selfincompatibility gene in apple to assess homozygocity in shoots obtained through haploid induction," Theoretical and Applied Genetics, vol. 96, no. 2, pp. 294-300, 1998.

[25] S. Long, M. Li, Z. Han, K. Wang, and T. Li, "Characterization of three new S-alleles and development of an S-allele-specific PCR system for rapidly identifying the $S$-genotype in apple cultivars," Tree Genetics and Genomes, vol. 6, no. 2, pp. 161-168, 2010.

[26] T. K. Hoy, G. Hattori, Y. Hirata et al., "Determination of selfincompatibility genotypes of Korean apple cultivars based on S-RNase PCR," Journal of Plant Biology, vol. 49, no. 6, pp. 448454, 2006.

[27] H. Kim, J. Park, Y. Hirata, and I. Nou, "Molecular characterization of new $S$-RNases (" $S_{31}$ " and " $S_{32}$ ") in apple (Malus $\times$ domestica Borkh.)," Journal of Plant Biology, vol. 51, no. 3, pp. 202-208, 2008.

[28] H. Kim, H. Kakui, N. Kotoda, Y. Hirata, T. Koba, and H. Sassa, "Determination of partial genomic sequences and development of a CAPS system of the $S$-RNase gene for the identification of 22 S haplotypes of apple (Malus $\times$ domestica Borkh.)," Molecular Breeding, vol. 23, no. 3, pp. 463-472, 2009.

[29] A. Matityahu, R. A. Stern, D. Schneider, and M. Goldway, "Molecular identification of a new apple S-RNaseS29-Cloned from "Anna", a low-chilling-requirement cultivar," HortScience, vol. 40, no. 3, pp. 850-851, 2005.

[30] D. Schneider, R. A. Stern, D. Eisikowitch, and M. Goldway, "Analysis of S-alleles by PCR for determination of compatibility in the "red delicious" apple orchard," Journal of Horticultural Science and Biotechnology, vol. 76, no. 5, pp. 596-600, 2001.

[31] K. Sakurai, S. K. Brown, and N. F. Weeden, "Determining the self-incompatibility alleles of Japanese apple cultivars," HortScience, vol. 32, no. 7, pp. 1258-1259, 1997.

[32] S. Matsumoto, K. Kitahara, T. Maejima, and H. Komatsu, "Parent-offspring relationships of apple cultivars "Shinano Piccoro" and "Komitsu" by S-RNase and SSR markers," Acta Horticulturae, vol. 763, pp. 303-308, 2007.

[33] R. Bošković and K. R. Tobutt, "Correlation of stylar ribonuclease isoenzymes with incompatibility alleles in apple," Euphytica, vol. 107, no. 1, pp. 29-43, 1999.

[34] W. Broothaerts, I. van Neram, and J. Keulemans, "Update on and review of the incompatibility $(S-)$ genotypes of apple cultivars," HortScience, vol. 39, no. 5, pp. 943-947, 2004.

[35] C. L. de Albuquerque Jr., F. Denardi, A. C. M. de Dantas, and R. O. Nodari, "The self-incompatible RNase $S$-alleles of Brazilian apple cultivars," Euphytica, vol. 181, no. 2, pp. 277-284, 2011.

[36] L. Garkava-Gustavsson, A. K. Brantestam, J. Sehic, and H. Nybom, "Molecular characterisation of indigenous Swedish apple cultivars based on SSR and S-allele analysis," Hereditas, vol. 145, no. 3, pp. 99-112, 2008.

[37] J. Halász, A. Hegedüs, Z. György, É. Pállinger, and M. Tóth, "S-genotyping of old apple cultivars from the Carpathian basin: methodological, breeding and evolutionary aspects," Tree Genetics \& Genomes, vol. 7, no. 6, pp. 1135-1145, 2011.

[38] Y. Adachi, S. Komori, Y. Hoshikawa et al., "Characterization of fruiting and pollen tube growth of apple autotetraploid cultivars showing self-compatibility," Journal of the Japanese Society for Horticultural Science, vol. 78, no. 4, pp. 402-409, 2009.

[39] S. Zafra-Stone, T. Yasmin, M. Bagchi, A. Chatterjee, J. A. Vinson, and D. Bagchi, "Berry anthocyanins as novel antioxidants in human health and disease prevention," Molecular Nutrition and Food Research, vol. 51, no. 6, pp. 675-683, 2007.

[40] A. Chan and T. B. Shea, "Dietary supplementation with apple juice decreases endogenous amyloid- $\beta$ levels in murine brain," Journal of Alzheimer's Disease, vol. 16, no. 1, pp. 167-171, 2009.

[41] F. Tchantchou, A. Chan, L. Kifle, D. Ortiz, and T. B. Shea, "Apple juice concentrate prevents oxidative damage and impaired maze performance in aged mice," Journal of Alzheimer 's Disease, vol. 8, no. 3, pp. 283-287, 2005.

[42] R. V. Espley, R. P. Hellens, J. Putterill, D. E. Stevenson, S. KuttyAmma, and A. C. Allan, "Red colouration in apple fruit is due to the activity of the MYB transcription factor, MdMYB10," Plant Journal, vol. 49, no. 3, pp. 414-427, 2007.

[43] H. Umemura, S. Otagaki, M. Wada, S. Kondo, and S. Matsumoto, "Expression and functional analysis of a novel MYB gene, $M d M Y B 110 a_{-} J P$, responsible for red flesh, not skin color in apple fruit," Planta, vol. 238, no. 1, pp. 65-76, 2013. 
[44] K. Sekido, Y. Hayashi, K. Yamada et al., "Efficient breeding system for red-fleshed apple based on linkage with $S_{3}$-RNase allele in 'Pink Pearl'" HortScience, vol. 45, no. 4, pp. 534-537, 2010.

[45] D. Chagné, K. Lin-Wang, R. V. Espley et al., "An ancient duplication of apple MYB transcription factors is responsible for novel red fruit-flesh phenotypes," Plant Physiology, vol. 161, no. 1, pp. 225-239, 2013. 


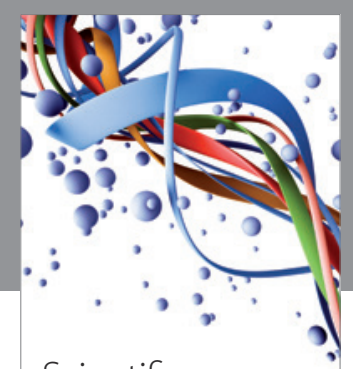

Scientifica
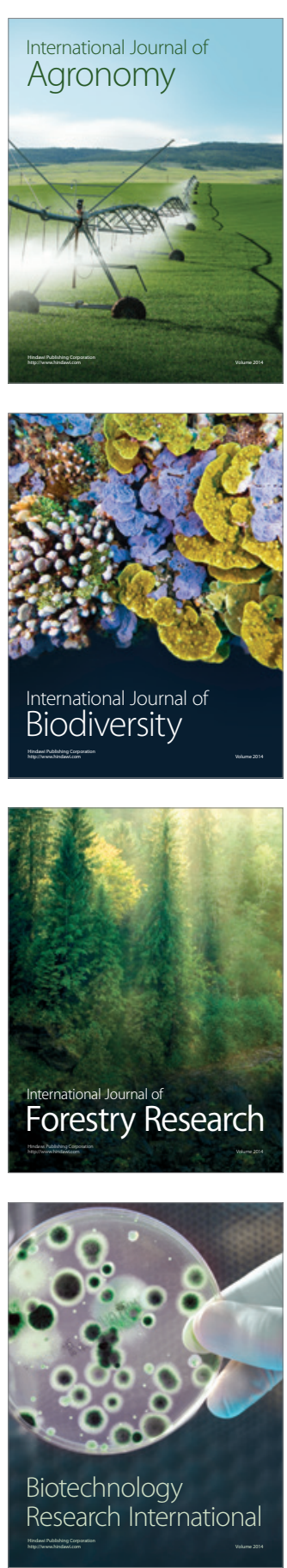
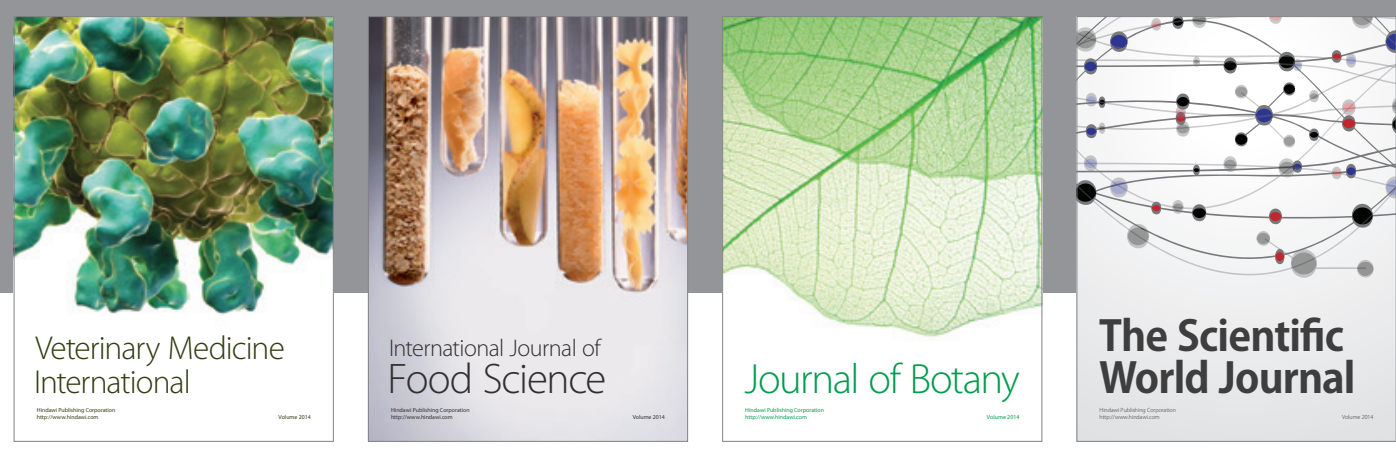

The Scientific World Journal
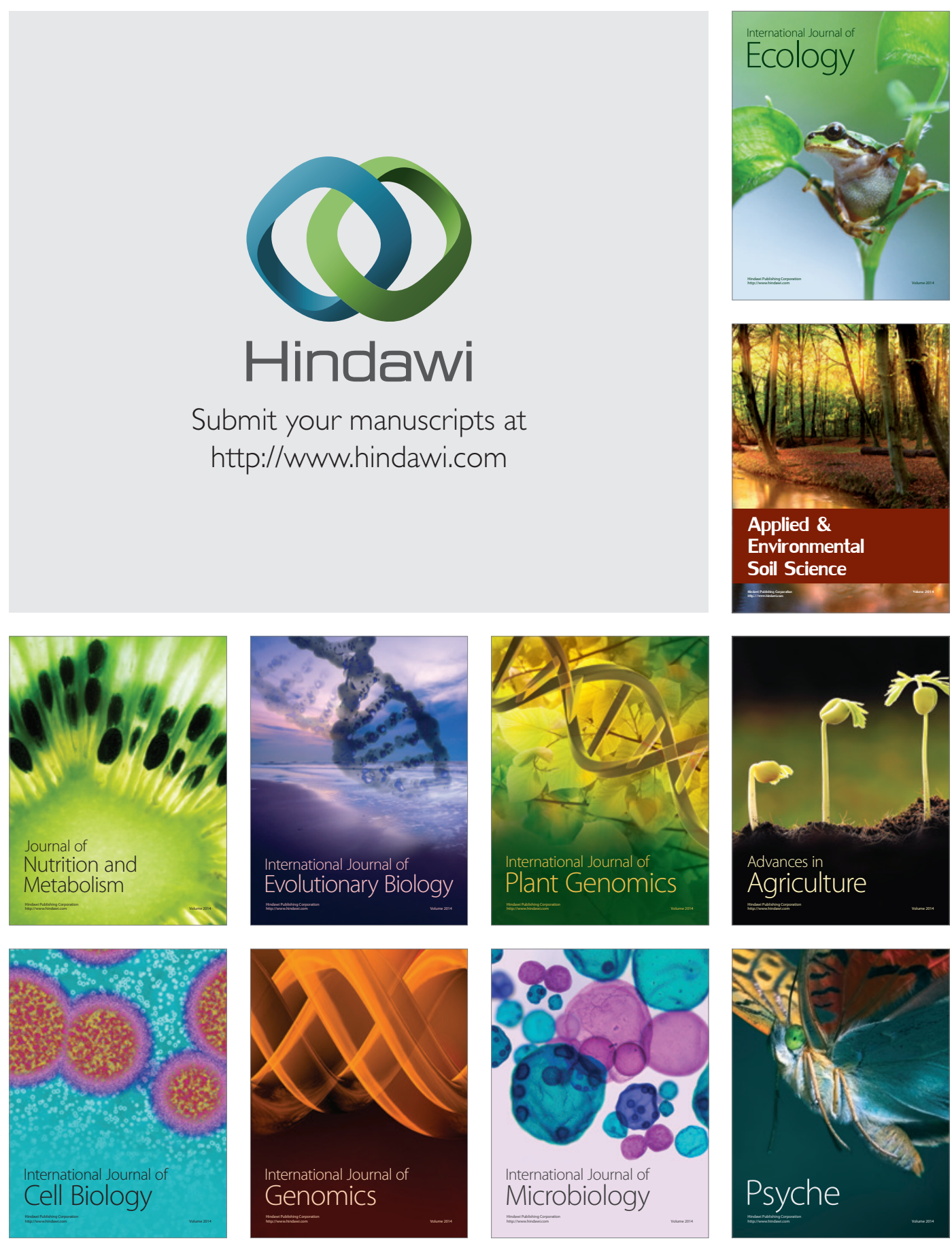